\title{
Prinsip Pencemar Membayar Untuk Mendorong Akses Kompensasi di Kebijakan ASEAN dalam Kasus Polusi Kabut Asap Lintas Batas
}

\section{Oleh: Gandar Mahojwala Paripurno ${ }^{1}$}

\begin{abstract}
Abstrak
Kebakaran hutan telah terjadi semenjak 1980-an dan tiga tahun lalu masih terjadi dengan dampak masif di Asia Tenggara. ASEAN selaku organisasi regional menjadi pelopor untuk membuat perjanjian asap lintas batas yang mengatur pencegahan asap lintas batas. Namun, tidak ada alur pemenuhan kompensasi untuk korban dalam perjanjian tersebut. Artikel ini mengargumentasikan bahwa Prinsip pencemar membayar (polluter-pays principle/PPP) dapat digunakan sebagai salah satu upaya dalam untuk memberikan akses kompensasi dari pencemar untuk korban. Terutama, dalam perkembangannya PPP menjadi prinseip yang memiliki banyak alternatif dalam alur pemberian kompensasi. Artikel ini merupakan tulisan yuridis-normatif dengan bentuk deskriptif.
\end{abstract}

Kata Kunci: prinsip pencemar membayar, polusi asap lintas batas, kompensasi.

\section{Abstract}

Forest fires have occurred since the 1980s and still occur until three years ago, with massive impacts in Southeast Asia. ASEAN as a regional organization pioneered the transboundary smoke agreement governing the prevention of transboundary haze. However, there is no scheme of compensation for victims in the agreement. This article argues that the

1 Penulis adalah Pengacara Publik di Lembaga Bantuan Hukum Yogyakarta. Penulis lulus dari Fakultas Hukum Universitas Islam Indonesaia dengan kekhususan Hukum Lingkungan. Penulis dapat dihubungi melalui gandarmahojwala@gmail.com. 
polluter-pays principle (PPP) can be used as an effort to provide compensatory access from polluters to victims. Particularly, in its development PPP became a principle that has many alternatives in the scheme of compensation. This article is a juridical-normative writing with a descriptive form.

Keywords: polluter-pays principle, transboundary haze peollution, compensation.

\section{Pendahuluan}

Dua tahun telah berlalu semenjak kebakaran hutan dan lahan (karhutla) bersamaan dengan kabut asap lintas batas terjadi di Asia Tenggara, walaupun kasus ini memang bukan hal yang baru dan telah terjadi semenjak 1980 dan 1990-an. ${ }^{2}$ Karhutla memang terjadi paling banyak di Sumatera dan Kalimantan ${ }^{3}$ sehingga penunjukkan atas tanggung jawab sangat lekat pada Indonesia. Padahal Indonesia, Malaysia, dan Singapura sama-sama berkepentingan dan mengambil untung dari agrobisnis di Indonesia. Kasus karhutla dan asap, baik yang terjadi pada 2015 maupun sebelumnya, tidak bisa dipisahkan dari teknik tebas dan bakar. ${ }^{4}$ Walaupun awalnya teknik ini hanya dilakukan oleh masyarakat lokal pada tahun $1994^{5}$ namun perkembangannya pun menjadi kebiasaan perusahaan. ${ }^{6}$

Di sisi lain, ASEAN sebagai organisasi regional sudah seharusnya dapat mengambil posisi untuk membuat strategi penanganan baik pada pencegahan kejadian di lapangan, hingga mengatur mekanisme paska kejadian asap lintas batas - termasuk pada mekanisme kompensasi. Namun hingga saat ini langkah Perjanjian AATHP (Asean Agreement on Transboundary Haze Pollution) sebagai upaya pusat dari ASEAN belum juga menciptakan persepakatan turunan maupun mekanisme untuk korban pencemaran dalam meraih hak atas kompensasi.

2 ASEAN Haze Action Online, Information on Fire and Haze, http://haze.asean.org/aboutus/information-on-fire-and-haze/

3 Ibid.

4 Indro Tjahjono, Hutan Kita Dibakar, (ISAI-SKEPHI, 1999), hlm. 13.

5 Yayat Ruchiat, "Penyebab dan Dampak Kebakaran Hutan dan Lahan: Studi Kasus Tumpang Titi, Kabupaten Ketapang, Kalimantan Barat," Makalah Lokakarya Perencanaan Proyek Community Development Through Rehabilitation of Imperata Grasslands Using Trees: A Model Approach Growing Vitex Pubescens for Charcoal Production in Kalimantan Indonesia (ACIAR). Pontianak: ACIAR, 2001, hlm. 1.

6 BBC News, "South East Asia Haze: What is Slash-and-Burn?", http://www.bbc.co.uk/news/ business-23026219 
Dalam hal pemenuhan kompensasi, sudah seharusnya ASEAN menggunakan instrumen polluter pays principle (PPP) untuk memberikan akses bagi korban asap lintas batas. PPP dikenal sebagai salah satu prinsip umum hukum internasional ${ }^{7}$ dan dianggap sebagai instrumen ekonomi yang paling mendasar ${ }^{8}$ dan efisien ${ }^{9}$ dalam kebijakan lingkungan modern. PPP juga telah menjadi dasar bagi banyak putusan lingkungan hidup dan diterima secara luas oleh negara-negara dan organisasi regional. ${ }^{10}$ Secara sederhana, PPP berarti biaya pengurangan polusi harus dibayar oleh pencemar, bukan oleh pemerintah. ${ }^{11}$ PPP dapat digunakan oleh organisasi regional - misalnya Uni Eropa yang telah berpengalaman mengadopsi PPP secara terus menerus - atau digunakan dalam peraturan domestik bagi tiaptiap negara. Prinsip ini sendiri dikenal sebagai peran penting dalam kebijakan lingkungan nasional dan internasional. ${ }^{12}$ Sehingga, implementasi prinsip ini secara penuh dapat dilakukan untuk meraih akses kompensasi dari pencemar untuk korban pencemaran, ${ }^{13}$ dan relevan untuk dilaksanakan pada konteks ASEAN secara organisasi regional dalam menghadapi kasus kabut asap lintas batas. Artikel ini mengargumentasikan bahwa PPP dapat digunakan sebagai salah satu upaya dalam untuk memberikan akses kompensasi dari pencemar untuk korban. Artikel ini merupakan tulisan yuridis-normatif dengan bentuk deskriptif.

\section{Prinsip Pencemar Membayar dalam Hukum Internasional}

\subsection{Awal Perkembangan Prinsip Pencemar Membayar}

PPP secara esensial adalah kebijakan ekonomi untuk mengalokasikan biaya polusi atau kerusakan lingkungan. ${ }^{14}$ Organisation for Economic Co-operation and

7 Malcolm N. Shaw, International Law, (New York: Cambridge University Press, 2008), hlm. 870.

8 Ibid.

9 Muhammad Munir, "History and Evolution of the Polluter Pays Principle: How an Economic Idea Became a Legal Principle?" Social Science Research Network. https://ssrn.com/abstract= 2322485. 2013, hlm. 2.

10 Dinah Shelton, Judicial Handbook on Environmental Law (Kenya: United Nations Environment Programme, 2005), hlm 6.

11 Ibid.

12 Margaret Rosso Grossman, "Agriculture and the Polluter Pays Principle: An Introduction," Oklahoma Law Review, Volume 59, 2006. US: University of Oklahoma College of Law, hlm. 3.

13 Patricia Birnie, International Law \& Environment, (UK: Oxford University Press, 2009), hlm. 324.

14 Patricia Birnie, Op.Cit., hlm. 322. 
Development (OECD) membuka jalan untuk adopsi formal bagi PPP. Praktek untuk melaksanakan PPP menjadi rekomendasi bagi negara-negara anggota OECD yang tertuang secara formal dalam sebagai “Guiding Principle Concerning the International Economic Aspects of Environmental Policies", ${ }^{15}$ yang mendapat penerimaan dan dukungan secara cepat. ${ }^{16}$

Konsep dasar dari prinsip panduan ini adalah internalisasi biaya eksternal. ${ }^{17}$ Biaya eksternal tumbuh saat aktivitas ekonomi maupun sosial dari suatu kelompok memberikan dampak pada kelompok lain, dan membutuhkan pencemar untuk membayar biaya pencegahan dan kontrol polusi. ${ }^{18}$ Namun, ukuran biaya pencegahan dan pengendalian pencemaran untuk harus direfleksikan dalam harga barang dan jasa yang menjadi sumber polusi. ${ }^{19}$ Diasumsikan bahwa agar biaya produksi tetap rendah, produsen akan berusaha mengurangi polusi. ${ }^{20}$ Ada beberapa cara untuk internalisasi, salah satu kemungkinannya dengan pajak lingkungan (eco-tax), yaitu dengan mengenakan pajak bahan bakar dan teknologi yang merusak lingkungan sesuai dengan biaya eksternal yang ditimbulkan. ${ }^{21}$ Namun, standar lingkungan yang diciptakan OECD tidak jelas, hanya menyatakan standar lingkungan adalah dalam 'keadaan yang dapat diterima'. ${ }^{22}$ Sehingga, konsep PPP dalam OECD masih membutuhkan banyak penjabaran.

PPP pada awalnya tidak lebih dari sekedar prinsip efisiensi untuk mengalokasikan biaya, sehingga pengurangan polusi tidak termasuk dalam konsepnya meskipun tidak ada batasan ataupun larangan untuk melakukannya. ${ }^{23}$ Prinsip ini juga tidak melarang implementasi yang mengarah pada hukuman untuk pencemar. ${ }^{24}$ Dengan kata lain, prinsip ini lebih didasarkan pada pertimbangan efisiensi dagang dan ekonomi daripada perbaikan dan perlindungan lingkungan. Sehingga awalnya PPP lebih dianggap sebagai prinsip ekonomi daripada prinsip

15 Ibid.

16 Ibid., hlm. 7.

17 Ibid., hlm. 4.

18 Margaret Rosso Grossman, Loc.Cit., hlm. 10.

19 Pierre-Marie Dupuy, International Environmental Law, (UK: United Kingdom, 2015), hlm. 72.

20 Patricia Birnie, Op.Cit.

21 Ibid.

22 Ibid.

23 Muhammad Munir, Loc.Cit., hlm. 10.

24 Ibid., hlm. 9. 
lingkungan. ${ }^{25}$ Terlepas dari kekurangannya, OECD merekomendasikan bagi negara-negara anggota untuk melindungi lingkungan dengan mengambil tindakan yang lebih luas. ${ }^{26}$

\subsection{Perkembangan Prinsip Pencemar Membayar Setelah OECD Guiding Principle}

Sejak Konfrensi PBB tentang Lingkungan dan Pembangunan 1992, PPP untuk pertama kalinya mendapat dukungan internasional sebagai sebuah kebijakan lingkungan. ${ }^{27}$ Langkah ini menggambarkan pentingnya prinsip sebagai prinsip fundamental yang diakui di tingkat global, ${ }^{28}$ tidak lagi seperti OECD yang terbatas pada negara-negara anggota.

Prinsip ke-16 dalam Deklarasi Rio - sebagai produk dari Konferensi PBB tentang Lingkungan dan Pembangunan - juga menekankan arti PPP yang diberikan oleh OECD. ${ }^{29}$ Deklarasi Rio menjelaskan bahwa otoritas nasional harus berusaha untuk mempromosikan internalisasi biaya lingkungan dan penggunaan instrumen ekonomi, dengan mempertimbangkan pendekatan bahwa pencemar pada prinsipnya harus menanggung biaya pencemaran, dengan memperhatikan kepentingan publik dan tanpa distorsi terhadap perdagangan internasional dan investasi. Walaupun, berdasarkan prinsip tersebut, tidak dapat dikatakan bahwa PPP dimaksudkan untuk mengikat secara hukum. ${ }^{30}$ Selain tidak memiliki karakter normatif dari sebuah peraturan hukum, ${ }^{31}$ ini juga berdasarkan sifat hukum lunak dari Deklarasi Rio. ${ }^{32}$

$25 \quad$ Ibid., hlm. 7.

26 Ibid., hlm. 9.

27 Patricia Birnie, Op.Cit., hlm. 322.

28 Ayobomi Olaniyan, "Imposing Liability for Oil Spill Clean-Ups in Nigeria: An Examination of the Role of the Polluter-Pays Principle" Journal of Law, Policy, and Globalization, Volume 40, 2015. IISTE, hlm. 76.

29 Ibid.

30 Patricia Birnie, Op.Cit.

31 Ibid.

32 Pierre-Marie Dupuy, Op.Cit., hlm. 72. 
Dalam perkembangannya, beberapa perjanjian setelah Rio mewajibkan pihakpihak perjanjian untuk menerapkan $\mathrm{PPP}_{,}^{33}$ dan lainnya menggunakan istilah panduan yang lebih lunak. ${ }^{34}$ PPP hanya muncul dalam beberapa perjanjian yang terbatas pada pencemaran saluran air internasional (watercourse), polusi laut, kecelakaan industri lintas batas, dan energi. ${ }^{35}$ Meskipun ada contoh implementasi secara lebih luas dalam kebijakan dan perundang-undangan nasional - misalnya dalam European Community Treaty - namun hal tersebut tidak berarti menunjukkan pola praktik dalam negara secara umum. ${ }^{36}$

Namun dalam perkembangannya sebagaimana dimaksud dalam Convention on Oil Pollution Preparedness, Response and Co-operation in 1990 dan Convention on the Transboundary Effects of Industrial Accidents in 1992, PPP diakui sebagai 'prinsip umum hukum lingkungan internasional' ${ }^{37}$ Prinsip umum hukum diakui sebagai sumber hukum internasional oleh Pasal 38 (1)(c) Statuta Mahkamah Internasional..$^{8}$

\subsection{Prinsip Pencemar Membayar dalam Perpsektif Hukum Internasional}

Prinsip umum hukum dipandang sebagai instrumen yang lemah, dikarenakan keterikatannya sering dipertanyakan, ${ }^{39}$ dan juga dianggap tidak tepat, samar, ${ }^{40}$ dan ketidakpastian dalam implementasi ${ }^{41}$ serta dikenal sebagai instrumen yang tidak dapat ditegakkan secara hukum. ${ }^{42}$ Sehingga, prinsip umum hukum masih bergantung pada pengakuan dalam perjanjian dan kebiasaan. Hal ini terlihat dari pendapat Mahkamah Internasional yang menyatakan bahwa prinsip umum

33 Mentioned in 1992 Paris Convention for the Protection of the Marine Environment of the NE Atlantic, Article 2(2)(b); 1992 Helsinki Convention on the Protection of the Marine Environment of the Baltic Sea Area, Article 3 (4); 1994 Danube River Protection Convention, Article 2(4); 1995 Barcelona Convention for the Protection of the Marine Environment and the Coastal Region of the Mediterranean, Article 4.

34 Mentioned in 1990 Convention on Oil Pollution Preparedness, Response and Cooperation, Preamble: 1992 Helsinki Convention on the Protection and Use of Transboundary Watercourses and Lakes, Article 2(5); 1995 Protocol to the Londong Dumping Convention, Article 3; 1999 Convention on the Protection of the Rhine, Article 4.

35 Patricia Birnie, Op.Cit., hlm. 322.

36 Ibid.

37 Malcolm N. Shaw, Op.Cit., hlm. 870.

38 Martin Dixon MA, International Law, (London: Blackstone Press Limited, 2000), hlm. 41.

39 Malcolm N. Shaw, Op.Cit., hlm. 279.

40 Ibid., hlm. 49.

$41 \quad$ Ibid., hlm. 871.

42 Ibid., hlm. 279. 
hukum membutuhkan penekanan dengan argumen yang terfokus baik pada kebiasaan maupun perjanjian internasional. ${ }^{43}$ Meskipun demikian, prinsip umum hukum masih dapat memberikan dampak mendasar terhadap perkembangan hukum internasional, baik memberikan alasan mengapa norma-norma tertentu harus diadopsi atau sebagai stimulus untuk praktik negara yang mengarah pada penciptaan kebiasaan dan perjanjian. ${ }^{44}$

Pada kondisi tertentu, sifat tidak tepat dari prinsip umum hukum adalah menguntungkan, karena prinsip ini menjadi mudah berkembang dan mengisi kondisi baru yang asing. Contohnya, dalam prinsip tidak merugikan (no harm principle) awalnya hanya untuk melindungi teritori bagi negara, namun implementasinya berkembang pada posisi perlindungan terhadap lingkungan baik didalam maupun diluar jurisdiksi negara. ${ }^{45}$

PPP sebagai prinsip umum hukum pun berkembang. Variasi yang berbeda dari PPP muncul, terutama pada kebutuhan untuk memberikan kompensasi segera untuk korban kerusakan lingkungan. ${ }^{46}$ Secara umum variasi tersebut menjadi tiga, yaitu instrumen pajak Pigouvian, instrumen ekonomi (market-based), dan atur dan awasi (command and control). ${ }^{47}$ Instrumen ekonomi dan atur dan awasi merupakan instrumen yang juga digunakan untuk memecahkan permasalahan eksternalitas. ${ }^{48}$ Atur dan awasi adalah instrumen yang dikenali dengan pendekatan peraturan atau standar, ${ }^{49}$ yang juga kerap disebut sebagai pendekatan konvensional yang kurang fleksibel..$^{50}$ Instrumen ekonomi mendorong perilaku melalui sinyal pasar, bukan melalui petunjuk eksplisit mengenai tingkat atau metode pengendalian

43 Ibid., hlm. 41.

44 Martin Dixon MA, Op.Cit., hlm. 41.

45 Pierre-Marie Dupuy, Op.Cit., hlm. 53.

46 Barbara Luppi, "The Rise and Fall of the Polluter-Pays Principle in Developing Countries", International Review of Law and Economics, Volume 32, 2012. Netherlands: Elsevier. Hlm. 135.

47 Ibid.

48 Muhammad Munir, "Implementation of the Polluter Pays Principle or Economic Approaches to Pollution: Command and Control, Taxes/Charges, and Tradable Discharges Permits (TDPs)" Social Science Research Network, https://papers.ssrn.com/sol3/papers.cfm?abstract $\underline{i d=2378796}$, hlm. 8 .

49 Ibid.

50 Richard L. Revesz, "Environmental and Policy", Social Science Research Network, https://papers. ssrn.com/sol3/papers.cfm?abstract_id $=552043, \mathrm{hlm} .33$ 
pencemaran..$^{51}$

PPP juga berkembang yang awalnya sebagai kebijakan yang berorientasi ekonomi, menjadi prinsip lingkungan untuk mencari pertanggungjawaban dari pencemar. ${ }^{52}$ Negara tidak lagi hanya menggunakan metode internalisasi dengan merefleksikan harga barang dan jasa, namun juga dengan aturan pajak, ataupun beban biaya.

Hal yang juga mempengaruhi perkembangan dan perbedaan dari penerapan PPP ialah dikarenakan tiap negara memiliki kapasitas lingkungan yang berbeda, terutama dalam berhadapan dengan polusi. ${ }^{53}$ Tiap negara juga memiliki tujuan dan prioritas sosial yang berbeda terkait perlindungan lingkungan, dan perbedaan pada tingkat industrialisasi dan kepadatan populasi. ${ }^{54}$ Dengan demikian, kebijakan lingkungan dari satu negara bagian ke negara lain akan berbeda, dan otoritas publik seperti pemerintah dan pengadilan dapat dan harus mempertimbangkan PPP dalam pengembangan hukum dan kebijakan lingkungan, 55 tetapi harus memutuskan cara menerapkan PPP untuk menjadi kewajiban yang mengikat, melalui instrumen kebijakan, peraturan, standar, atau instrumen ekonomi ${ }^{56}$ yang meliputi standar proses dan produk, peraturan dan larangan bagi individual, atau biaya polusi. ${ }^{57}$ Sehingga, PPP tidak dapat dianggap sebagai aturan yang kaku dan diterapkan secara seragam pada semua kasus. ${ }^{58}$

\subsection{PPP Sebagai Akses Kompensasi Untuk Korban Pencemaran}

Variasi implementasi PPP ada untuk menjamin kompensasi bagi korban pencemaran. ${ }^{59}$ Komisi Hukum Internasional juga mendukung upaya dengan menyatakan bahwa 'PPP adalah komponen penting untuk menjamin bahwa

51 Ibid.

52 Patricia Birnie, Op.Cit., hlm. 322.

53 Muhammad Munir, Loc.Cit., hlm. 12.

54 Ibid.,

55 Patricia Birnie, Op.Cit., hlm. 323.

56 Jean-Philippe Barde, “Economic Instruments in Environmental Policy; Lessons From the OECD Experience and Their Relevance to Developing Economies", OECD Development Centre Working Paper No. 92. France: OECD, 1994, hlm. 6.

57 Margaret Rosso Grossman, Loc.Cit., hlm. 7.

58 Ibid.

59 Mizan R. Khan, Loc.Cit., hlm. 645. 
korban yang menderita atas kerusakan dari insiden yang berkaitan dengan aktifitas berbahaya mampu mendapatkan kompensasi yang segera dan memadai'. ${ }^{60}$ Namun unsur subjektif negara juga mempengaruhi variasi tersebut menjadi berbeda-beda. ${ }^{61}$ Dalam mengimplementasikan dalam instrumen hukum, tidak semua negara menyebut terminologi 'prinsip pencemar membayar', namun menggunakan konsep dari prinsip tersebut tanpa menggunakan istilahnya. ${ }^{62}$ Banyak perundang-undangan lingkungan hidup sesuai dengan kondisi ini. ${ }^{63}$

Beberapa implementasi PPP yang paling sering dilakukan negaranegara adalah dengan internalisasi melalui pajak ataupun denda, dan juga aturan tentang pertanggungjawaban melalui proses hukum perdata maupun publik. Selain melaksanakan PPP untuk kepentingan efek jera bagi pencemar ${ }^{64}$ dengan mencabut lisensi pencemar, denda, ataupun hukuman pidana, ${ }^{65}$ negara dengan memberlakukan PPP dapat mencari kompensasi dari pencemar, dan menghubungkannya pada pembayaran kompensasi untuk korban pencemaran dan melakukan pemulihan dan konservasi lingkungan. ${ }^{66}$ Fungsi ini sekaligus melengkapi pemenuhan prinsip pencegahan. ${ }^{67}$ Implementasi PPP dengan proses perdata dapat membuka akses bagi korban untuk menuntut kompensasi langsung ke pencemar tanpa campur tangan pemerintah. ${ }^{68}$ Keuntungan lain tuntutan perdata adalah mengembangkan pendekatan berbasis hak terhadap masalah lingkungan. ${ }^{69}$ Upaya perdata memang menjadi peluang dikarenakan kasus polusi lintas batas maupun domestik sebagian besar disebabkan oleh pihak privat, dan menyebabkan pihak privat lain menjadi korban. ${ }^{70}$

60 Patricia Birnie, Op.Cit., hlm. 324.

61 Ibid., hlm. 323.

62 Margaret Rosso Grossman, Loc.Cit., hlm. 32.

63 Ibid.

64 Chen-Ju Chen, "The Liability and Compensation Mechanism under International Marine Environmental Law: Adopting the Polluter Pays Principle to Control Marine Pollution under International Law from Aspect of International Cooperation", LOSI Conference Papers, Conference on Securing the Ocean for the Next Generation, California: LOSI, 2012, hlm. 10.

65 Ibid.

66 Margaret Rosso Grossman, Loc.Cit., hlm. 9.

67 Ibid., hlm. 32.

68 Ibid.

69 Ibid.

70 Ibid. 


\section{Tantangan atas Kabut Asap di Asia Tenggara}

Kasus kabut asap yang terjadi di Asia Tenggara pada tahun 2015 lalu dapat menjadi momentum bangkitnya kerjasama ASEAN untuk kembali bekerja sama dalam mengatasi kebakaran hutan yang secara faktual lintas kepentingan berbagai negara. Perlu dipahami bahwa pertanggungjawaban tidak dapat diletakkan hanya pada Indonesia, terutama dengan melihat bahwa kepentingan bisnis dari agrobisnis dinikmati Singapura dan Malaysia melalui perusahaannya, yang disisi lain juga menjadi korban kabut asap. Hal ini terlihat dari lima puluh persen kepemilikan lahan perkebunan di Indonesia dimiliki oleh asing, terutama perusahaan Malaysia dan Singapura. ${ }^{71}$ Malaysia juga merupakan investor nomer satu dalam sektor kelapa sawit di Indonesia. ${ }^{72}$ Namun, isu perusahaan tersebut tidak didiskusikan dan tidak mendapat perhatian dalam negosiasi perjanjian AATHP (Asean Agreement on Transboundary Haze Pollution) dikarenakan dinilai terlalu sensitif. ${ }^{73}$ Padahal, ASEAN juga memahami bahwa pembakaran lahan adalah sumber utama dari asap. ${ }^{74}$

Perjanjian AATHP merupakan upaya pusat dari ASEAN untuk memberantas asap. ${ }^{75}$ Persetujuan ini pada intinya meminta pihak-pihak untuk melakukan, antara lain, (i) tindakan legislatif dan administratif untuk mencegah dan mengendalikan kegiatan yang berkaitan dengan kebakaran hutan dan lahan dan hutan yang dapat mengakibatkan pencemaran lintas batas, dan (ii) tindakan bersama dan nasional untuk mengintensifkan kerja sama regional dan internasional untuk mencegah, menilai, dan memantau pencemaran kabut lintas batas yang berasal dari darat dan

71 Helena Varkkey, “Transboundary Haze and Human Security in Southeast Asia: National and Regional Perspectives", Georgetown Journal of Asian Affairs, 3(1), 2016. US: Georgetown University, hlm. 44.

72 Daniel Helimann, "After Indonesia's Ratification: The ASEAN Agreement on Transboundary Haze Pollution and its Effectiveness As a Regional Environmental Governance Tool," Journal of Current Southeast Asian Affairs, Volume 34 (3) (2015) hlm. 109.

73 Euston Quah, "The Political Economy of Transboundary Pollution: Mitigation Forest Fires and Haze in Southeast Asia", dalam The Asian Community - Its Concepts and Prospects. Tokyo: Soso Sha. (2013), hlm. 18.

74 Ibid.

75 Daniel Helimann, Loc.Cit., hlm. 96. 
hutan. ${ }^{76}$ Perjanjian AATHP menekankan pada kooperasi, koordinasi, dan konsultasi antara para pihak. ${ }^{77}$ Sementara itu, AATHP memiliki kelemahan berkaitan dengan ketidakadaan dalam penanganan masalah teknis yang penting, seperti: (i) tidak ada mekanisme penyelesaian sengketa dengan jelas ${ }^{78}$; (ii) tidak ada kewajiban dan sanksi yang ditetapkan ${ }^{79}$ dan; (iii) tidak ada ganti rugi secara langsung. ${ }^{80}$ Ketiadaan mekanisme pencarian ganti rugi maupun kompensasi untuk korban menunjukkan bahwa Perjanjian AATHP tidak mengadopsi PPP. Bagaimanapun, ganti rugi adalah salah satu aspek penting dari PPP. ${ }^{81}$

\section{Implementasi PPP dalam Skema Kompensasi}

\subsection{Mengejar Pemenuhan Kompensasi dengan Implementasi Polluter Pays Principle dalam konteks Hak Akses yang Setara untuk Upaya Perbaikan Tingkat Nasional}

Dalam menjamin hak-hak korban, salah satu elemen penting dari PPP adalah hak akses yang setara untuk upaya perbaikan tingkat nasional (equal rights to access national remedies). Hak ini bertujuan memberikan perlakuan setara untuk korban pencemaran domestik maupun lintas batas untuk mengakses perbaikan dari negara asal pencemaran. ${ }^{82}$ Hak ini termasuk akses untuk informasi, partisipasi dalam pemeriksaan administratif dan proses hukum, dan penerapan standar non-diskriminatif untuk menentukan ilegalitas pencemaran domestik maupun lintas batas. ${ }^{83}$ Hak ini tidak dapat dipisahkan dengan prinsip non-diskriminasi dikarenakan keterkaitannya yang dekat. Non-diskriminasi menekankan pentingnya pemulihan domestik (yang dapat dilakukan melalui aturan-aturan domestik maupun internasional) untuk menjamin bahwa keuntungan dari perbaikan dan

76 Fadhilah Abdul Ghani, “Review on ASEAN Transboundary Haze Pollution Agreement 2002: Problems and Solutions," Journal of Humanities, Language, Culture, and Business, Volume 1(1), (2017) hlm. 156.

77 Daniel Helimann, Loc.Cit., hlm. 111.

$78 \quad$ Ibid.

79 Apichai Sunchindah, Loc.Cit.

80 Daniel Helimann, Loc.Cit., hlm. 108.

81 Patricia Birnie, Op.Cit., hlm. 324.

82 Chen-Ju Chen, Loc.Cit., hlm. 10.

83 Ibid. 
prosedurnya diperluas hingga penggugat lintas batas. ${ }^{84}$ Sehingga, korban diluar jurisdiksi negara mendapatkan alur akses langsung untuk pemulihan domestik dari negara dimana pencemaran dan sumber kerusakan berasal. Juga, menjamin bahwa pencemar lintas batas menjadi subjek hukum yang tidak lebih ringan dari pencemaran domestik. ${ }^{85}$

Namun dengan melaksanakan hak akses yang setara dan non-diskriminasi, tidak lantas implementasi PPP terhadap korban lintas batas menjadi mudah. Perlu dipastikan pula penyelesaian masalah hukum seperti pilihan hukum (choice of law) dan yurisdiksi bagi hukum perdata internasional dan harmonisasi hukum nasional yang berkaitan dengan pertanggungjawaban atas kerusakan lingkungan. Deklarasi Rio dan Stockholm tidak menunjukkan dukungan secara jelas atas prinsip nondiskriminasi ${ }^{86}$ namun Komisi Hukum Internasional memberikan dukungan yang konsisten dalam konteks kasus lingkungan lintas batas. ${ }^{87}$ Subjek bagi hak ini tidak hanya untuk individual, namun juga organisasi non-pemerintah dan otoritas publik. Hal ini yang perlu dikejar dalam pembuatan kerangka-kerangka kebijakan ASEAN setelah Perjanjian AATHP. Harmonisasi aturan-aturan tersebut yang seharusnya dilakukan oleh ASEAN dalam perjanjian paska AATHP. Terutama, melihat kondisi ASEAN yang masih sulit untuk memberikan akses kompensasi dalam kerangka litigasi, dikarenakan cara-cara litigasi dipandang kontradiksi dengan nilai-nilai ASEAN khususnya prinsip non-intervensi dan kedaulatan (sovereignty). ${ }^{88}$

Harmonisasi tidak terbatas pada aturan ASEAN dengan PPP, namun juga kebijakan lingkungan apa yang akan ditentukan dan diterapkan bagi negara anggota. Dengan demikian, kebijakan lingkungan dari satu negara bagian ke negara lain akan keterkaitan.

\subsection{Reinterpretasi PPP dalam Government-Pays dan Victim-Pays}

Dalam mengedepankan hak kompensasi bagi korban, beberapa negara

84 Patricia Birnie, Op.Cit., hlm. 304.

85 Ibid., hlm. 305.

86 Ibid.

87 Ibid.

88 Daniel Helimann, Loc.Cit., hlm. 110. 
memberlakukan metode pemerintah-membayar (government-pays). ${ }^{89}$ Metode tersebut dilakukan untuk menjamin kompensasi efektif dan tepat waktu. Sehingga, pemerintah mempercepat pemenuhan hak kompensasi bagi korban pencemaran. ${ }^{90}$ Metode pemerintah-membayar sering dilakukan ketika pencemar tidak dapat diidentifikasi atau pailit, ${ }^{91}$ maupun saat kompensasi memakan waktu lama. ${ }^{92}$ Metode ini menyusun ulang dasar pemikiran orisinil dari PPP. ${ }^{93}$ Reinterpretasi ini menetapkan pemerintah daerah dan pemerintah pusat bersama-sama menanggung kerusakan lingkungan. ${ }^{94}$ Sehingga, kelak pemerintah menggantikan korban untuk mencari kompensasi dari pencemar. Prinsip subrogasi dapat dilaksanakan oleh pemerintah ke pencemar. ${ }^{95}$

Namun dalam konteks untuk mengurangi tingkat polusi, beberapa negara memilih untuk melakukan metode korban-membayar (victim-pays). Metode ini dilakukan oleh suatu negara untuk membujuk negara lain untuk mengurangi polusi. ${ }^{96} \mathrm{Hal}$ ini juga berarti negara yang lingkungannya telah dicemari (korban) memberikan bantuan finansial kepada negara yang menyebabkan pencemaran (pencemar). ${ }^{97}$ Dengan begitu, pencemar mendapatkan subsidi untuk melakukan upaya kontrol polusi. ${ }^{98}$ OECD memahami bahwa pada beberapa kasus, PPP harus diabaikan dalam melakukan victim-pays. ${ }^{99}$ Walaupun, implementasi victim-pays bukan merupakan kontradiksi atas pelaksanaan PPP. ${ }^{100}$

Tentu, harus ada persepakatan bentuk interpretasi mana yang akan dilaksanakan dari negara-negara anggota ASEAN dalam mengimplementasikan interpretasi diatas. Termasuk, dalam konteks mana ASEAN akan membuat 89 Barbara Luppi, Loc.Cit., hlm. 142.

90 Mizan R. Khan, Polluter-Pays-Principle: The Cardinal Instrument for Addressing Climate Change, Laws, Volume 4, 2015. Switzerland: MDPI, hlm. 645.

91 Ibid.

92 Ibid.

93 Ibid.

94 Barbara Luppi, Loc.Cit., hlm. 142.

95 Ibid.

96 Patricia Birnie, Op.Cit., hlm. 325.

97 Hyung-Jin Kim, "Subsidy, Polluter Pays Principle and Financial Assitance among Countries," Journal of World Trade, Volume 34(6), 2000. Netherlands: Kluwer Law International. Hlm. 129.

98 Jean-Philippe Barde, Loc.Cit. hlm. 6.

99 Hyung-Jin Kim, Loc.Cit., hlm. 129.

100 Ibid., hlm. 133. 
target dalam kebijakannya. Implementasi government-pays jelas mengedepankan kompensasi untuk korban dengan cara pemenuhan secepat mungkin dengan pendanaan yang dibayarkan oleh pemerintah terlebih dahulu. Sedangkan untuk upaya pencegahan, victim-pays dapat menjadi alternatif untuk dipertimbangkan dalam implementasinya, mengingat bahwa ada relasi ekonomi yang kuat diantara ketiga negara (Singapura, Indonesia, Malaysia) dan kepentingan bisnis di perkebunan Indonesia.

\section{Penutup}

Memang, baik Indonesia, Singapura, dan Malaysia memiliki kepentingan di balik kebakaran di Indonesia dan tidak akan dapat diselesaikan hanya dengan pendekatan kesepakatan bersama ASEAN, tanpa ada keinginan politik dari tiap negara. PPP dalam bentuk implementasi maupun variasinya dapat menjadi rujukan dalam mendorong kompensasi untuk korban dari polusi udara yang terjadi di ASEAN, ataupun menjadi instrumen pencegahan. Hal tersebut dapat dilaksanakan ASEAN, walaupun sebagai organisasi regional yang memiliki kondisi politik dan keputusan kebijakan yang bersifat diplomatis.

Tentu, PPP tidak lantas menjadi prinsip sapu jagad. Beberapa hal perlu dipersiapkan terutama oleh negara-negara yang berdampak dan mempunyai relasi langsung dengan kabut asap ini dan juga kesiapan ASEAN sebagai organisasi regional yang akan menjadi penentu kebijakan regional pula. Perlu untuk menetukan target kedepan dari kebijakan lingkungan yang akan ditentukan oleh ASEAN, tentu dengan mempertimbangkan kepentingan-kepentingan yang lekat pada Singapura, Indonesia, dan Malaysia. 


\section{Daftar Pustaka}

ASEAN Haze Action Online. Information on Fire and Haze, http://haze.asean. org/about-us/information-on-fire-and-haze/, diakses tanggal 1 November 2017.

Tjahjono, Indro. 1999. Hutan Kita Dibakar. Indonesia: ISAI-SKEPHI.

Ruchiat, Yayat. "Penyebab dan Dampak Kebakaran Hutan dan Lahan: Studi Kasus Tumpang Titi, Kabupaten Ketapang, Kalimantan Barat". Makalah Lokakarya Perencanaan Proyek Community Development Through Rehabilitation of Imperata Grasslands Using Trees: A Model Approach Growing Vitex Pubescens for Charcoal Production in Kalimantan Indonesia (ACIAR). Pontianak: ACIAR, 2001.

BBC News, South East Asia Haze: What is Slash-and-Burn?, http://www.bbc. co.uk/news/business-23026219, diakses tanggal 1 November 2017.

Shaw, Malcolm N. 2008. International Law. New York: Cambridge University Press.

Munir, Muhammad. 2013. "History and Evolution of the Polluter Pays Principle: How an Economic Idea Became a Legal Principle?" Social Science Research Network. https:/ / ssrn.com/abstract=2322485, 2013.

Shelton, Dinah. 2005. Judicial Handbook on Environmental Law, Kenya: United Nations Environment Programme.

Rosso Grossman, Margaret. 2006. “Agriculture and the Polluter Pays Principle: An Introduction," Oklahoma Law Review, Volume 59, 2006. US: University of Oklahoma College of Law.

Birnie, Patricia. 2009. International Law E Environment. UK: Oxford University Press.

Dupuy, Pierre-Marie. 2015. International Environmental Law. UK: Cambridge University Press.

Olaniyan, Ayobomi. 2015. “Imposing Liability for Oil Spill Clean-Ups in Nigeria: An Examination of the Role of the Polluter-Pays Principle," Journal of Law, Policy, and Globalization, Volume 40, 2015. IISTE.

Dixon MA, Martin. 2000. International Law, London: Blackstone Press Limited. 
Barde, Jean-Philippe. 1994. "Economic Instruments in Environmental Policy; Lessons From the OECD Experience and Their Relevance to Developing Economies," OECD Development Centre Working Paper No. 92. France: OECD.

Climate Action. UN Environment Chief Calls for Polluters to Pay for Environmental Damage- Not Taxpayers, http://www.climateactionprogramme.org/ news/un-environment-chief-calls-for-polluters-to-pay-for-environmentaldamage-no/, diakses tanggal 1 November 2017.

Khan, Mizan R. 2015. “Polluter-Pays-Principle: The Cardinal Instrument for Addressing Climate Change," Laws, Volume 4, 2015. Switzerland: MDPI.

Kim, Hyung-Jin. 2000. “Subsidy, Polluter Pays Principle and Financial Assitance among Countries," Journal of World Trade, Volume 34(6), 2000. Netherlands: Kluwer Law International.

Varkkey, Helena. 2016. “Transboundary Haze and Human Security in Southeast Asia: National and Regional Perspectives", Georgetown Journal of Asian Affairs, Volume 3(1), 2016.

Chen, Chen-Ju. 2012. "The Liability and Compensation Mechanism under International Marine Environmental Law: Adopting the Polluter Pays Principle to Control Marine Pollution under International Law from Aspect of International Cooperation," LOSI Conference Papers, Conference on Securing the Ocean for the Next Generation, University of California, 2012.

Luppi, Barbara. 2012 “The Rise and Fall of the Polluter-Pays Principle in Developing Countries", International Review of Law and Economics, Volume 32, 2012. Netherlands: Elsevier.

Quah, Euston. 2013. “The Political Economy of Transboundary Pollution: Mitigation Forest Fires and Haze in Southeast Asia", dalam The Asian Community Its Concepts and Prospects. Tokyo: Soso Sha.

Helimann, Daniel. 2015. “After Indonesia's Ratification: The ASEAN Agreement on Transboundary Haze Pollution and its Effectiveness As a Regional Environmental Governance Tool," Journal of Current Southeast Asian Affairs, Volume 34(3), 2015. German: GIGA. 
Mustafa, Maizatun. 2016. “The Position of Environmental Law in Malaysia in Dealing with Domestic and Regional Air Pollution Problems", Jurnal Sultan Alauddin Sulaiman Shah, Volume 3 (2), 2016. Malaysia: Universiti Islam Antarbangsa Selangor.

Nurul Alfia, Ayu. 2016. “Tanggung Jawab Perusahaan Transnasional dalam Kebakaran Hutan di Riau dalam Perspektif Hukum Internasional," Diponegoro Law Journal, Volume 5(3), 2016. Semarang: Universitas Diponegoro.

Adolf, Huala. 2011. Hukum Ekonomi Internasional: Suatu Pengantar. Bandung: Keni Media.

The Jakarta Post, Pulp Firm Bumi Mekar Hijau Found Guilty of Starting Illegal Fires, http://www.thejakartapost.com/news/2016/08/31/pulp-firm-bumimekar-hijau-found-guilty-of-starting-illegal-fires-.html/, diakses tanggal 1 November 2017.

BBC News, Dapatkah Kebakaran Hutan di Indonesia Diakhiri?, http:/ / www.bbc. com/indonesia/berita_indonesia/2016/03/160314_indonesia_kebakaran_ hutan_2016/, diakses tanggal 1 November 2017.

Tempo, Kebakaran Hutan, PT Bumi Mekar Hijau Cuma Bayarar Rp. 78 Miliar, https:/ / bisnis.tempo.co/read/800226/kebakaran-hutan-pt-bumi-mekar-hijau-cuma-bayar-rp-78-miliar/, diakses tanggal 1 November 2017.

Khee-Jin TAN, Alan. 2015. “The Haze Crisis in Southeast Asia: Assessing Singapore's Transboundary Haze Pollution Act 2014," National University of Singapore Working Paper 2015/002, 2015. Singapore: National University of Singapore.

Sunchindah, Apichai. 2015. “Transboundary Haze Pollution Problem in Southeast Asia: Reframing ASEAN's Response," ERIA Discussion Paper Series, 2015. Jakarta: ERIA.

Fadhilah Abdul Ghani, 2017. "Review on ASEAN Transboundary Haze Pollution Agreement 2002: Problems and Solutions," Journal of Humanities, Language, Culture, and Business, Volume 1(1). 
